\title{
Java plum (Syzygium cumini) extract cream effect on decreasing the number of sunburn cell on the dorsal skin of male Wistar rat (Rattus norvegicus) exposed to UV-radiation
}

\author{
Dinesh Tanabbal', \\ I Gusti Ayu Dewi Ratnayanti², \\ I Gusti Nyoman Sri Wiryawan², \\ I Gusti Kamasan Nyoman Arijana², \\ Ida Ayu Ika Wahyuniari²

\section{'Medical Education Programme, Faculty of Medi- cine, Udayana University, \\ ${ }^{2}$ Department of Histology, Faculty of Medicine, Udayana University, \\ JL. PB Sudirman, Dangin Puri Kelod, Denpasar Barat, Kota Denpasar, Bali, Indonesia}

\begin{abstract}
Background: The primary acute damage due to UV radiation is keratinocyte apoptosis or sunburn cell. Previous studies showed that antioxidants inhibit UV damage. Java plum (Syzygium cumini) which is found in Indonesia, was known to have a high concentration of antioxidants. This study was aimed to assess the Java plum ethanol extract cream effects on the number of sunburn cells on the dorsal skin of male Wistar rats that exposed to UV-B.

Methods: This experimental research was a post-test only control group design that was conducted on 30 male rats. Groups were divided into control, placebo, 5\%, 10\%, and 20\% ethanol extract cream concentrations (P1, P2, P3, P4, and P5, respectively). The number of sunburn cell were then observed and recorded based on visual evaluation of the skin biopsy under a light microscope.

Results: The mean results of P1, P2, P3, P4, and P5 were 132.67, 98.67, 118.67, 104.00, and 54.67 respectively. The control, placebo, $5 \%$, and $10 \%$ ethanol extract cream showed no significant result ( $p>0.05$ ). In contrast, $20 \%$ ethanol extract cream showed a protective effect $(p<0.05)$. Conclusion: Java plum ethanol extract cream with $20 \%$ dose could decrease the number of sunburn cells in the skin.
\end{abstract}

Keywords: cell apoptosis, $U V-B$, antioxidant, skin aging, anthocyanin

\section{Introduction}

Aging is a process that causes physical and functional changes in the body. ${ }^{1}$ Since Indonesia has a tropical climate, Indonesian people are exposed to sunlight almost 10 to 12 hours a day. This shows that their skin is in high risk of aging due to Ultraviolet (UV) irradiation also known as photo aging. ${ }^{2}$

Two types of ultraviolet rays are emitted through sunlight and contact the human skin, which are the UV-A and UV-B which cause acute and chronic effects on the skin. The acute effects includes erythema, sunburn, rising of skin temperature, thickening of the skin, pigmentation problem and blockage of vitamin D production whereas, chronic effects are photoaging and skin cancer. UV-A radiation penetrates human skin reaching the dermis and causes the collagen fibers and elastin proteins in the dermis layer to destroy which results in less elasticity of skin and formation of wrinkles on it. Next, the UV-B acts on the epidermis and affects the number of Langerhans cell, keratinocytes, and melanocytes resulting in redness and sunburn to the skin. ${ }^{3}$ Keratinocyte with DNA damage due to over-exposure to UV-B activates p53 protein to aid in the repair process of the damaged DNA. However, if the repair process fails due to its severity, the p53 protein turns into the initiator of cell apoptosis. Thus, the damaged keratinocyte undergoes apoptosis and forms 
sunburn cells, that result in skin redness and pain. ${ }^{4}$

Human skin has antioxidants which protect it against reactive oxygen species. Antioxidants are molecules that inhibit the oxidation of other atoms by sharing its electron to other atoms. However, over-exposure of the skin towards UV radiation leads to a significant reduction of the antioxidant, thus increasing oxidative stress. ${ }^{5}$ Java plum (Syzygium cumini) or also known as jambolan is a purple colored oblong fruit. The fruit and seeds have been reported to be rich in anthocyanin which belongs to a parent class of molecules called flavonoids, a well-known antioxidant, which accounts for the scavenging of free radicals and protective effect of antioxidant enzymes. ${ }^{6}$ Flavonoids are divided into five subgroups according to their different chemical structures which are the anthoxanthins, flavanones, flavanonols, flavans, and anthocyanidins. Java plum is found to be rich in anthocyanidins which are also aglycones of anthocyanin. Anthocyanin that is found in Java plum is in the form of delphinidin-3-gentiobioside, malvidin-3-laminaribioside, petunidin-3-gentiobioside, cyanidin diglycoside, petunidin, and malvidin. ${ }^{7}$ Previous study shows that anthocyanin prevents acute and chronic effects of UV irradiation. ${ }^{8}$ Considering the activity of anthocyanin in oxidative stress, further research is needed to understand the effect of Java plum on keratinocyte apoptosis due to UV irradiation.

\section{Method}

The methods of the research are, preparation of extract, $5 \mathrm{~kg}$ of Java plum was sorted and processed to get $60 \mathrm{~g}$ of extract. Java plum ethanol extract was then processed to form $5 \%, 10 \%$, and $20 \%$ of Java plum ethanol extract cream. Next, a total of 30 samples were divided into 5 groups which are the control group (P1), placebo group (P2), 5\% Java plum ethanol extract cream group (P3), 10\% Java plum ethanol extract cream group (P4), and 20\% Java plum ethanol extract cream group (P5). The rats were shaved on their dorsal skin with measurements of $4 \times 4 \mathrm{~cm}$. The shaved skin of the rats was exposed under UV-B with $2000 \mathrm{~mJ} / \mathrm{cm} 2$ for 400 seconds. The skin of rats in control group (P1) was not applied with any substance before exposure to UV-B, the skin of rats in first treatment group (P2), second treatment group (P3), third treatment group (P4), and fourth treatment group (P5) were applied with placebo, 5\% Java plum ethanol extract cream, 10\% Java plum ethanol extract cream, and 20\% Java plum ethanol extract cream respectively 1 hour before exposure to UV-B. After exposure, the rats were applied with their respective creams in each group. Skin biopsy was taken after 24 hours then processed and stained by hematoxylin-eosin (HE). The number of sunburn cells in the epidermis was observed under a light microscope with 400x magnification. Sunburn cells were counted in 5 visual fields and the result was divided by epidermal length resulting in sunburn cell $/ \mathrm{mm}$. The results are observed and recorded. Throughout the experiment, the animal subjects are handled ethically without causing any harm or death.
Descriptive analysis was conducted to obtain a central tendency value (mean and median) and standard deviation (SD) of the dependent variable. Statistical analysis was conducted to test the normality of the data using the Shapiro-Wilk test, homogeneity of the data by Levene's test and proceeded with test parametric statistics with one-way ANOVA. Least Significance Difference (LSD) test was performed to analyze the difference between each group.

\section{Result}

The average number of sunburn cell on the dorsal skin of the Wistar rat in Group P1, P2, P3, P4, and P5 were 132.67, 98.67, 118.67, 104.00 , and 54.67 , respectively. These results were analyzed by using one way ANOVA method with a significance value of $\mathrm{p}<0.05$. Table 2 showed that there was no significant difference between the number of sunburn cells $(\mathrm{p}=0.225)$. Statistical analysis of the number of sunburn cells in experimental animals was continued using the Least Significant Difference (LSD) test. From the LSD results, it was found that cell assessment data differed significantly $(\mathrm{p}<0.05)$ between group P1 (Control) and P5 (20\%). Based on the post hoc test results, the mean difference between $\mathrm{P} 1$ and P5 is significant at the 0.05 level (Table 3 ).

Table 1. Descriptive test result of number of sunburn cells on the dorsal skin of Wistar rat.

\begin{tabular}{lcccccc}
\hline Group & $\begin{array}{c}\text { Number of } \\
\text { sample (n) }\end{array}$ & $\begin{array}{c}\text { Mean } \\
\text { (cell/mm) }\end{array}$ & STD & Median & Minimum & Maximum \\
& 6 & 132.67 & 77.125 & 146.00 & 40 & 232 \\
\hline P1 (Control) & 6 & 98.67 & 36.192 & 94.00 & 52 & 148 \\
\hline P2 (Placebo) & 6 & 118.67 & 61.380 & 138.00 & 40 & 188 \\
\hline P3 (5\%) & 6 & 104.00 & 66.501 & 78.00 & 28 & 208 \\
\hline P4 (10\%) & 6 & 54.67 & 40.292 & 50.00 & 4 & 112 \\
\hline P5 (20\%) & 6 & & & & & \\
\hline
\end{tabular}

Table 2. Result of number of sunburn cells on the dorsal skin of Wistar rat analysed by using One-Way ANOVA method.

\begin{tabular}{cccc}
\hline & Sum of Squares & Mean Square & Sig. \\
\hline Between Groups & 20840.533 & 5210.133 & 0.225 \\
\hline Within Groups & 85357.333 & 3414.293 & \\
\hline Total & 106197.867 & & \\
\hline
\end{tabular}

Table 3. Post-Hoc result of number of sunburn cells on the dorsal skin of Wistar rat analysed by using the Least Significant Difference (LSD) test.

\begin{tabular}{llllll}
\hline & P1 & P2 & P3 & P4 & P5 \\
\hline P1 & - & 0.323 & 0.682 & 0.404 & 0.029 \\
\hline P2 & 0.323 & - & 0.559 & 0.876 & 0.204 \\
\hline P3 & 0.682 & 0.559 & - & 0.667 & 0.069 \\
\hline P4 & 0.404 & 0.876 & 0.667 & - & 0.156 \\
\hline P5 & 0.029 & 0.204 & 0.069 & 0.156 & -
\end{tabular}


The number of sunburn cells were observed under light microscope (400x magnification) as shown in Figure 1.

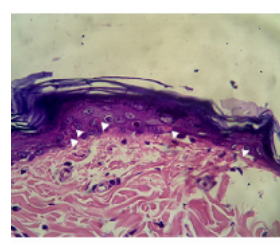

(P1)

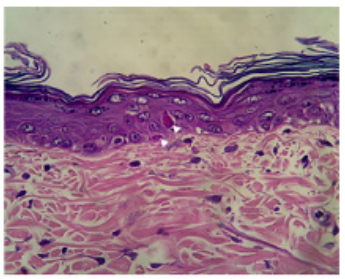

(P4)

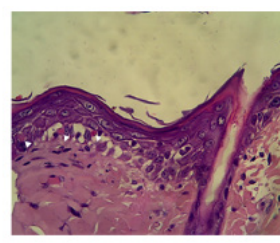

(P2)

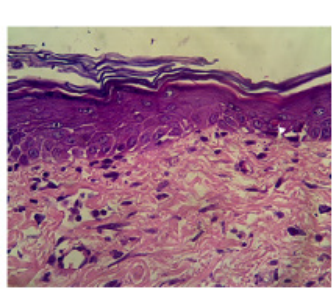

(Ps)
Figure 1. Results of number of sunburn cells on the dorsal skin of male Wistar rat observed under light microscope. There was no significant difference between groups ( $p>0.05)$, except the number of sunburn cells is lower in group P5 than P1 $(p<0.05)$.

\section{Discussion}

The skin covers and protects the whole outside surface of the human body from exposure to bright (UV) radiation, trauma, extreme temperatures, poisons, and microbes. The integument comprises of two commonly subordinate layers, the epidermis, and dermis, which lay on a greasy subcutaneous layer, the panniculus adipose. The epidermis consists of important cells such as keratinocyte, melanocytes, Langerhans cell, and Merkel cells. Several studies, including the present one, demonstrate that antioxidant enhances skin structure and give photoprotective impacts. ${ }^{9}$

Data on the number of sunburn cells on the dorsal skin of male Wistar rat from the treatment group of a placebo, cream of $5 \%$, and $10 \%$ concentration of Java plum ethanol extract showed an equal number with the results from the control group. The data from samples treated with $20 \%$ concentration of Java plum ethanol extract cream showed the ability to reduce the number of sunburn cells on the dorsal skin of the male Wistar rat. This means that the administration of cream with a higher concentration of Java plum ethanol extract can reduces the number of sunburn cells.

The results of this study are supported by other researches. A human study showed that flavonoids called catechins found in green tea decreased the number of sunburn cells and proved that it is suitable for protection from ultraviolet radiaton and sunburn. ${ }^{10}$ Bolfa et al.,${ }^{11}$ conducted an animal study of Romanian propolis and its photoprotective effects against UV-B. Romanian propolis is collected from plant resins by bees and is known as one of the most abundant sources of polyphenols. The study suggests that the polyphenol content in Romanian propolis minimized the number of sunburn cells in the skin of mice. ${ }^{11}$ Research by Krismayogi et al.,$^{8}$ on the capability of purple cabbage in reducing erythema due to UV irradiation. Anthocyanin in the purple cabbage managed to reduce the erythema score of the back skin of the Wistar rat. Java plum (Syzygium cumini) is rich in anthocyanin which has the properties of protecting the skin against UV effects. Generally, antioxidant scavenges free radicals and prevents cell oxidation which contributes to skin aging. ${ }^{12}$ Anthocyanin inhibits protein oxidation, elevation of cyclobutane pyrimidine dimers (CPD) and 8-dihydro-2'-deoxyguanosine (8-OHdG) suggesting the protective effects against the oxidative damage to proteins and DNA. ${ }^{13}$ Anthocyanin also protects from cell damage which results in apoptosis of keratinocytes by strongly absorbing the visible and UV spectrums, with maximum absorbance in the ranges of $500 \mathrm{~nm}-600 \mathrm{~nm} .{ }^{14} \mathrm{An}$ other proven property of anthocyanin are inhibition of UV-induced translocation of the transcription factors NF-KB and AP-1 and other inflammatory responses in keratinocytes. Anthocyanin was also found to prevent the UV-induced over-expression of IL-8, caspase-3 activation, and DNA fragmentation in human keratinocytes. ${ }^{15}$ These properties of anthocyanin have been proved in this study with the results that show a high concentration of Java plum ethanol extract cream reduces the number of sunburn cells on the back skin of male Wistar rats.

Some factors have been identified as the limitation of this research, firstly the subjective method of counting the number of sunburn cells from the observed area which could show different results if done by a different researcher. Second, no phytochemical test was conducted on the Java plum ethanol extract directly by the researcher which caused the failure to identify the type of antioxidant elements found in the Java plum extract.

\section{Conclusion}

Based on the results of the research that has been done, it can be concluded that cream with the concentration of $20 \%$ Java plum ethanol decreases the number of sunburn cells on the dorsal skin of the male Wistar rat. Further research is needed to understand other protective effects and its mechanism.

\section{Acknowledgment}

The authors would like to thank all of the supervisors in the Department of Histology, Faculty of Medicine, Udayana University for all the technical assistance and valuable discussions during the study.

\section{References}

1. Zhang S, Duan E. Fighting against skin aging. Cell Transplantation. 2018;27(5):729-38. DOI: 10.1177/0963689717725755

2. Aji A, Erwinda E, Yusrawati Y, et al. Vitamin D deficiency status and its related risk factors during early pregnancy: a cross-sectional study of pregnant Minangkabau women, Indonesia. $B M C$ Pregnancy and Childbirth. 2019;19(1):183. DOI: 10.1186/ s12884-019-2341-4

3. D'Orazio J, Jarrett S, Amaro-Ortiz A, et al. UV radiation and the skin. International Journal of Molecular Sciences. 2013;14(6):12222-48. DOI: 10.3390/ijms140612222 
4. Craig S, Earnshaw C, Virós A. Ultraviolet light and melanoma. The Journal of Pathology. 2018;244(5):578-85. DOI: 10.1002/ path.5039

5. Mueller J, Heckathorn S, Fernando D. Identification of a chloroplast dehydrin in leaves of mature plants. International Journal of Plant Sciences. 2003;164(4):535-42. DOI: 10.1086/375376

6. Do Carmo Brito B, da Silva Pena R, Santos Lopes A, et al. Anthocyanins of jambolão (Syzygium cumini): extraction and pH-dependent color changes. Journal of Food Science. 2017; 82(10):2286-90. DOI: 10.1111/1750-3841.13847

7. Ayyanar M, Subash-Babu P. Syzygium cumini (L.) skeels: A review of its phytochemical constituents and traditional uses. Asian Pacific Journal of Tropical Biomedicine. 2012;2(3):2406. DOI: 10.1016/s2221-1691(12)60050-1

8. Krismayogi G, Ratnayanti I, Linawati N, et al. Purple cabbage extract cream effect on erythema score of male Wistar rats back skin exposed to UV-B radiation. Biomedical and Pharmacology Journal. 2018;11(1):343-51. DOI: 10.13005/bpj/1378

9. Dunaway S, Odin R, Zhou L, et al. Natural antioxidants: Multiple mechanisms to protect skin from solar radiation. Frontiers in Pharmacology. 2018;9:392. DOI: 10.3389/fphar.2018.00392

10. Mnich C, Hoek K, Virkki L, et al. Green tea extract reduces induction of p53 and apoptosis in UVB-irradiated human skin in- dependent of transcriptional controls. Experimental Dermatology. 2009;18(1):69-77. DOI: 10.1111/j.1600-0625.2008.00765.x

11. Olfa P, Vidrighinescu R, Petruta A, et al. Photoprotective effects of Romanian propolis on skin of mice exposed to UVB irradiation. Food and Chemical Toxicology. 2013;62:329-42. DOI: 10.1016/j.fct.2013.08.078

12. Poljšak B, Dahmane R. Free radicals and extrinsic skin aging. Dermatology Research and Practice. 2012;2012:1-4. DOI: 10.1155/2012/135206

13. Afaq F, Syed D, Malik A, et al. Delphinidin, an anthocyanidin in pigmented fruits and vegetables, protects human hacat keratinocytes and mouse skin against UVB-mediated oxidative stress and apoptosis. Journal of Investigative Dermatology. 2007;127(1):222-32. DOI: 10.1038/sj.jid.5700510

14. Merzlyak M, Chivkunova O, Solovchenko A, et al. Light absorption by anthocyanins in juvenile, stressed, and senescing leaves. Journal of Experimental Botany. 2008;59(14):3903-11. DOI: $10.1093 / \mathrm{jxb} / \mathrm{ern} 230$

15. Cimino F, Ambra R, Canali R, et al. Effect of cyanidin-3-o-glucoside on UVB-induced response in human keratinocytes. Journal of Agricultural and Food Chemistry. 2006;54(11):4041-47. DOI: $10.1021 / \mathrm{jf060253x}$ 